\title{
Impact of Population Mixing Between a Vaccinated Majority and Unvaccinated Minority on Disease Dynamics: Implications for SARS-CoV-2
}

David N. Fisman MD MPH ${ }^{1}$, Afia Amoako MPH ${ }^{1}$ and Ashleigh R. Tuite PhD MPH',

${ }^{1}$ Dalla Lana School of Public Health, University of Toronto, Toronto, Ontario, Canada

${ }^{2}$ Centre for Immunization Readiness, Public Health Agency of Canada, Ottawa, Ontario, Canada

\section{Address reprint requests and correspondence to:}

David Fisman, MD MPH FRCP(C)

Room 686, 155 College Street, Toronto, Ontario, M5T 3M7

Email: david.fisman@utoronto.ca

Funding statement: The research was supported by a grant to DNF from the Canadians

Institutes for Health Research (2019 COVID-19 rapid researching funding OV4-170360).

Declaration of competing interests: DNF has served on advisory boards related to influenza and SARS-CoV-2 vaccines for Seqirus, Pfizer, Astrazeneca and Sanofi-Pasteur Vaccines, and has served as a legal expert on issues related to COVID-19 epidemiology for the Elementary Teachers Federation of Ontario and the Registered Nurses Association of Ontario. ART was employed by the Public Health Agency of Canada when the research was conducted. The work does not represent the views of the Public Health Agency of Canada. 
It is made available under a CC-BY-NC-ND 4.0 International license .

\begin{abstract}
Background: The speed of vaccine development has been a singular achievement during the SARS-CoV-2 pandemic. However, anti-vaccination movements and disinformation efforts have resulted in suboptimal uptake of available vaccines. Vaccine opponents often frame their opposition in terms of the rights of the unvaccinated. Our objective was to explore the impact of mixing of vaccinated and unvaccinated populations on risk among vaccinated individuals.

Methods: We constructed a simple Susceptible-Infectious-Recovered (SIR) compartmental model of a respiratory infectious disease with two connected sub-populations: vaccinated individuals and unvaccinated individuals. We simulated a spectrum of patterns of mixing between vaccinated and unvaccinated groups that from random mixing to like-with-like mixing (complete assortativity). We evaluated the dynamics of an epidemic within each subgroup, and in the population as a whole, and also evaluated the contact-frequency-adjusted contribution of unvaccinated individuals to risk among the vaccinated.
\end{abstract}

Results: As expected, the relative risk of infection was markedly higher among unvaccinated individuals than among vaccinated individuals. However, the contact-adjusted contribution of unvaccinated individuals to infection risk during the epidemic was disproportionate, with unvaccinated individuals contributing to infection risk among the vaccinated at a rate up to 6.4 times higher than would have been expected based on contact numbers alone in the base case. As assortativity increased, the final attack rate decreased among vaccinated individuals, but the contact-adjusted contribution to risk among vaccinated individuals derived from contact with unvaccinated individuals increased.

Interpretation: While risk associated with avoiding vaccination during a virulent pandemic accrues chiefly to the unvaccinated, the choices of these individuals are likely to impact the health and safety of vaccinated individuals in a manner disproportionate to the fraction of unvaccinated individuals in the population. 


\section{Introduction}

The remarkable speed of vaccine development, production and administration is a singular human achievement during the SARS-CoV-2 pandemic (1). While the ability to vaccinate to herd immunity has been held back by the increasing transmissibility of novel variants of concern (e.g., Delta and Omicron variants) $(2,3)$, and global distribution of vaccines is deeply inequitable (4), the effectiveness of vaccines against acquisition of infection, in reducing severity of disease, and in disrupting onward transmission even when breakthrough infections occur, is likely to have saved many lives.

However, the longstanding and growing anti-vaccine movement, combined with wellorganized disinformation efforts, have resulted in suboptimal uptake of readily available vaccines in many countries, with adverse health and economic consequences for communities and individuals (5-7). Those who oppose vaccination, and community mandates (e.g., "vaccine passports") that provide incentives for vaccination, often invoke the rights of individuals to opt out of such programs $(8,9)$.

Such arguments disregard the wider harms that may result from non-vaccination, in both vaccinated and unvaccinated individuals, in populations with substantial levels of vaccination opt-out. While assortative (like-with-like) mixing (10) is characteristic of many communicable disease systems, and this may be expected to limit interaction between vaccinated and unvaccinated populations to some degree, the normal functioning of society, mean that complete assortativity is not a phenomenon observed in reality. Furthermore, the dominant airborne mode of spread of SARS-CoV-2 (11) means that close-range physical mixing of individuals from vaccinated and groups is not necessary for between-group disease transmission.

Simple mathematical models can often provide important insights into the behavior of complex communicable disease systems $(10,12,13)$. To better understand the implications of the interplay between vaccinated and unvaccinated populations under different assumptions 
about population mixing, we constructed a simple SIRS model to reproduce the dynamics of interactions between vaccinated and unvaccinated population subgroups in a highly vaccinated population. Our objectives were to contrast contribution to epidemic size and risk estimates by sub-population; and (ii) to understand the impact of assortativity on expected disease dynamics.

\section{Methods}

\section{Model}

We constructed a simple Susceptible-Infectious-Removed model of a respiratory viral disease, as in (14). The model was subdivided into two connected sub-populations: vaccinated individuals and unvaccinated individuals (Figure 1). The model is governed by the following ordinary differential equations, where $i$ represents the vaccination status of the group, and $j$ represents vaccination status of contacts.

$$
\begin{aligned}
\mathrm{dS}_{\mathrm{i}} / \mathrm{dt} & =-\beta \Sigma \mathrm{f}_{\mathrm{ij}}\left(\mathrm{I}_{\mathrm{j}} / \mathrm{N}_{\mathrm{j}}\right) \\
\mathrm{dI} \mathrm{I}_{\mathrm{i}} / \mathrm{dt} & =\beta \Sigma \mathrm{f}_{\mathrm{ij}}\left(\mathrm{I}_{\mathrm{j}} / \mathrm{N}_{\mathrm{j}}\right)-\gamma \mathrm{I}_{\mathrm{i}} \\
\mathrm{dR}_{\mathrm{i}} / \mathrm{dt} & =\gamma \mathrm{I}_{\mathrm{i}}
\end{aligned}
$$

Here $\beta$ represents the product of contacts per unit time and probability of transmission per contact, which is considered equivalent in vaccinated and unvaccinated individuals, and estimated as $R_{o} / D$, where $D$ is the duration of infectivity and $R_{0}$ is the basic reproduction number. In order to capture non-random mixing between vaccinated and unvaccinated subpopulations, we modeled frequency-dependent transmission, with assortativity modeled using the approach of Garnett and Anderson (10). The parameter $\mathrm{f}_{\mathrm{ij}}$ in the model above represents the fraction of contacts in the $\mathrm{i}^{\text {th }}$ group with infectious individuals in the $\mathrm{j}^{\text {th }}$ group, where again the groups in question are vaccinated or unvaccinated. We use a constant of assortativity $(\eta)$ in our 
medRxiv preprint doi: https://doi.org/10.1101/2021.12.14.21267742; this version posted December 16, 2021. The copyright holder for this

It is made available under a CC-BY-NC-ND 4.0 International license .

mixing matrix; when $\eta$ is closer to o mixing is closer to random, while values closer to 1 represent extreme assortativity.

Individuals gained immunity after recovery from infection but we also assumed that some fraction of the unvaccinated population had immunity at baseline due to prior infection. We also assumed that a fraction of the population was vaccinated at baseline. Immunity following vaccination was treated as an all or none phenomenon, with only a fraction of vaccinated individuals (as defined by vaccine efficacy) entering the model in the immune state and the remainder left in the susceptible state. In this simple model we assume a closed population with durable immunity. Our model was otherwise parameterized to represent a disease similar to SARS-CoV-2 infection with Delta variant, with an $\mathrm{R}_{0}=6(15)$, and other parameter values as described in Table 1.

We used the model to explore the impact of varying rates of immunization and different levels of assortativity on the dynamics of disease in vaccinated and unvaccinated subpopulations. We evaluated the absolute contribution to overall case counts by these subpopulations, as well as within-group and overall infection risk. Attack rates were calculated as the cumulative number of infections divided by the population size. We calculate a quantity that we denote $\psi$, which we define as the cumulative incidence of infections among the vaccinated that derive from contact with unvaccinated individuals, divided by the fraction of the population that is unvaccinated. A version of the model in Microsoft Excel is available at 10.6084/m9.figshare.15189.576.

\section{Results}

The simulated epidemic is presented in Figure 2. With 20\% baseline immunity among unvaccinated individuals, and $80 \%$ of the population vaccinated, the absolute number of cases from vaccinated and unvaccinated groups was similar; however, after adjustment for 
substantially larger population in the vaccinated group, risk of infection was markedly higher among unvaccinated individuals during the epidemic, with the incidence rate ratio rising as high as 16 at the epidemic's peak. Post-epidemic incidence was lower among unvaccinated individuals than among vaccinated individuals, as the explosive epidemic among unvaccinated individuals resulted in a lower fraction of these individuals in the susceptible compartment as the epidemic waned. The contact-adjusted contribution of unvaccinated individuals to infection risk during the epidemic was disproportionate, with unvaccinated individuals contributing to infection risk among the vaccinated at a rate up to 6.4 times higher than would have been expected based on contact numbers alone shortly before the epidemic's peak (Figure 3). Varying assortativity resulted in changes in epidemic size in the vaccinated population; as assortativity increased (i.e., with reduced contact between vaccinated and unvaccinated populations) the final attack rate decreased among vaccinated individuals, but the value of $\psi$ (cumulative total fraction of infections derived from contact with unvaccinated individuals divided by the fraction of contacts with unvaccinated individuals) increased. This pattern was consistent across a range of values for vaccine efficacy and reproduction numbers (Figure 4). 
medRxiv preprint doi: https://doi.org/10.1101/2021.12.14.21267742; this version posted December 16, 2021. The copyright holder for this

It is made available under a CC-BY-NC-ND 4.0 International license .

\section{Discussion}

We use a simple deterministic model to explore the impact of assortative mixing on disease dynamics and contribution to risk in a partially vaccinated population during a pandemic modeled on the current pandemic of SARS-CoV-2. Notwithstanding the model's simplicity, it provides a graphical representation of the expectation that even with highly effective vaccines, and in the face of widespread vaccination, a substantial fraction of new cases can be expected to occur in vaccinated individuals, such that rates, rather than absolute numbers, represent the appropriate metric for presenting vaccination impacts. However, we find that the degree to which people differentially interact with others who are like themselves is likely to have an important impact on disease dynamics, and on risk in individuals who choose to get vaccinated.

Many vaccine opponents have framed vaccine adoption as a matter of individual choice. However, we demonstrate here that the choices made by individuals who forgo vaccination contribute to risk among those who do. Indeed, when adjusted for share of the population vaccinated, we find that the contribution of risk by unvaccinated individuals to vaccinated individuals is disproportionate. Increased mixing between vaccinated and unvaccinated groups increases final epidemic size among vaccinated individuals; conversely, more assortative mixing decreases final epidemic size, but results in enhancement of the degree to which risk among vaccinated individuals can be attributed to unvaccinated individuals. The fact that this excess contribution to risk cannot be mitigated by separating groups undermines the assertion that vaccine choice is best left to the individual, and supports strong public actions aimed at enhancing vaccine uptake and limiting access to public spaces for unvaccinated individuals, as risk cannot be considered "self-regarding”(16).

The simplicity of our model is both a strength (as it provides a system that is transparent and easily modified to explore the impact of uncertainty) and a weakness, because it does not precisely simulate a real-world pandemic process in all its complexity. However, one advantage 
of models is that they provide a ready platform for layering on increasing complexity, so our model can be adapted to incorporate additional structural elements or alternate assumptions.

In summary, this mathematical model demonstrates that while risk associated with avoiding vaccination during a virulent pandemic accrues chiefly to the unvaccinated, the choices of these individuals are likely to impact the health and safety of vaccinated individuals in a manner disproportionate to the fraction of unvaccinated individuals in the population. Risk among unvaccinated individuals cannot be considered self-regarding, and considerations around equity and justice for individuals who do choose to be vaccinated, as well as those who choose not to be, need to be considered in the formulation of vaccination policy. 
medRxiv preprint doi: https://doi.org/10.1101/2021.12.14.21267742; this version posted December 16, 2021. The copyright holder for this preprint (which was not certified by peer review) is the author/funder, who has granted medRxiv a license to display the preprint in perpetuity.

It is made available under a CC-BY-NC-ND 4.0 International license .

Table 1. Model Parameters

$\begin{array}{cccc}\text { Parameter description } & \text { Symbol } & \text { Value } & \text { Plausible } \\ & \text { Range } & \text { Reference }\end{array}$

Probability of transmission per contact *

$\beta \quad 437$

$164-728$

Calculated

number contacts per year

Rate of recovery from infection (per year)

$\gamma$

73

$41-91$

Basic reproduction number $\left(\mathrm{R}_{0}\right)$

$\mathrm{R}_{0}$

6

4-8

Mixing between subpopulations $(0=$

$\eta$

0.5

$0-1$

Assumption,

random, 1 = assortative)

approach based on

Proportion vaccinated

$\mathrm{P}_{\mathrm{v}}$

0.8

$---$

Vaccine efficacy

VE

0.8

0.7-0.9

Population (N)

$\mathrm{N} \quad 10,000,000$

Baseline immunity in unvaccinated

0.2

$0.1-0.5$

Assumption 
medRxiv preprint doi: https://doi.org/10.1101/2021.12.14.21267742; this version posted December 16, 2021. The copyright holder for this preprint (which was not certified by peer review) is the author/funder, who has granted medRxiv a license to display the preprint in perpetuity.

It is made available under a CC-BY-NC-ND 4.0 International license .

\section{Figures}

\section{Figure 1. Model schematic.}

The model is a closed system without births or deaths. Individuals are susceptible (S), infectious (I) or immune (R), and are assigned to a vaccinated or unvaccinated subpopulation, denoted by subscript "v" or "u", respectively. Force of infection is defined by mixing within and between groups under varying assumptions about assortativity. Here $\beta$ represents the product of contact rate in a group times infection probability following effective contact. The fraction of contacts among individuals in the $\mathrm{i}^{\text {th }}$ group (e.g., vaccinated or unvaccinated), with those in the $\mathrm{j}^{\text {th }}$ group is denoted $\mathrm{f}_{\mathrm{ij}}$. The rate of recovery is denoted $\gamma$. The model assumes durable immunity.
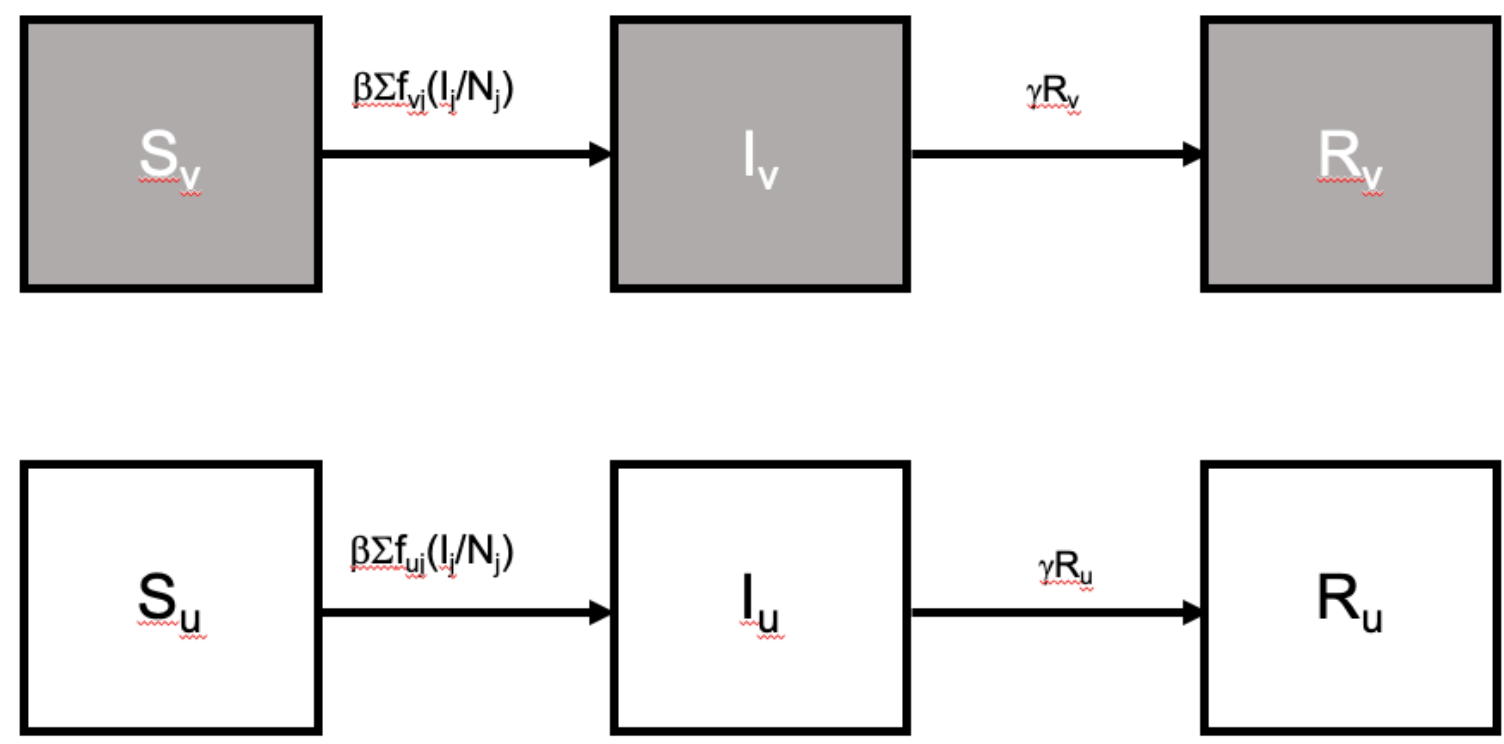


\section{Figure 2. Simulated epidemic.}

(A) Absolute case numbers. Most cases are unvaccinated (orange curve), but the difference in absolute case numbers is small, as most of the population is vaccinated. (B) Risk among vaccinated (orange) and unvaccinated (green curve) individuals. Risk is far lower among the vaccinated, with a large relative risk of infection among the unvaccinated (dashed curve).

Results are shown for a mixing coefficient $(\eta)$ of 0.5 and VE of 0.80 . Time is shown in years.
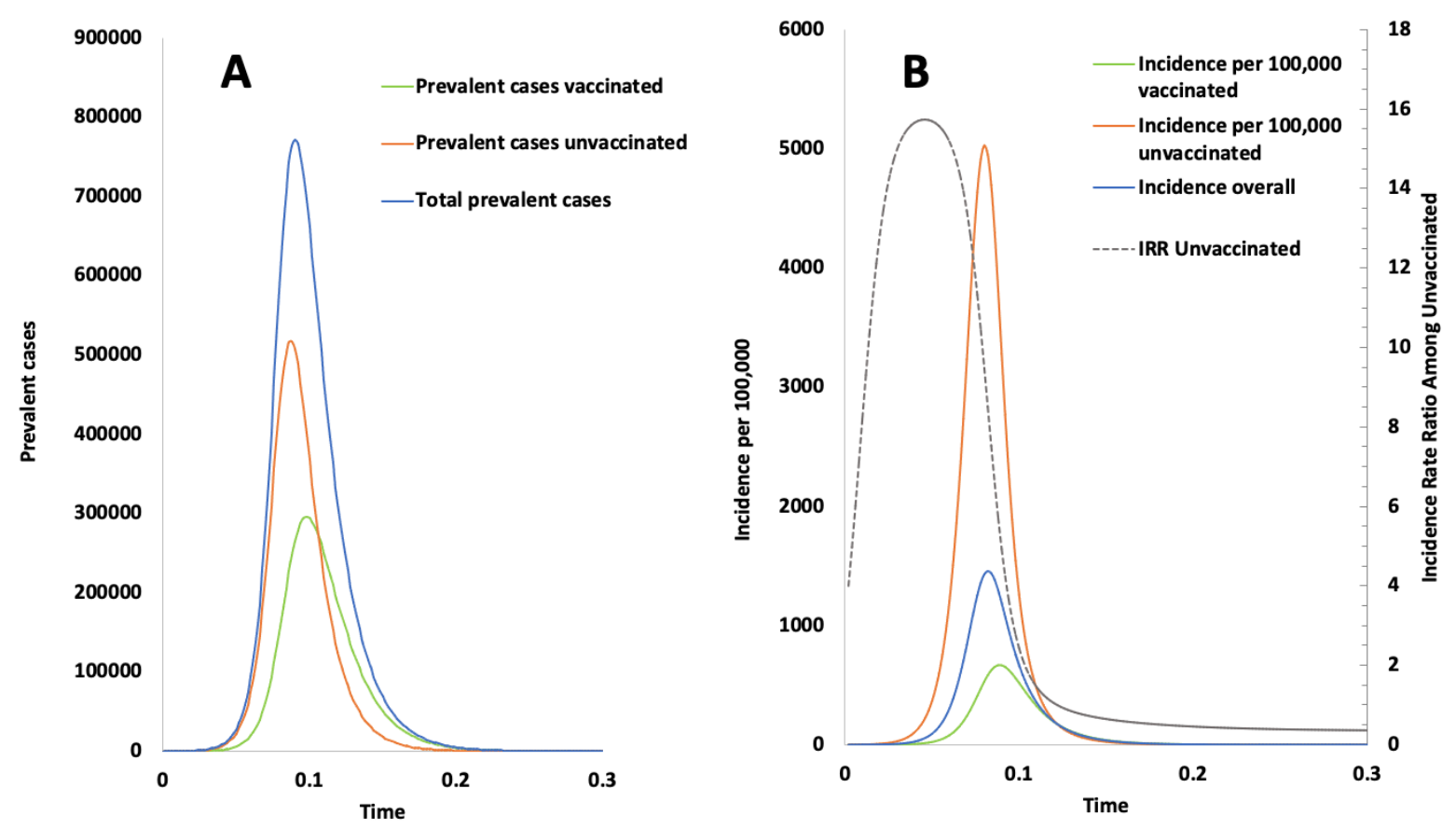
medRxiv preprint doi: https://doi.org/10.1101/2021.12.14.21267742; this version posted December 16, 2021. The copyright holder for this preprint (which was not certified by peer review) is the author/funder, who has granted medRxiv a license to display the preprint in perpetuity.

It is made available under a CC-BY-NC-ND 4.0 International license .

Figure 3. The contribution of risk to vaccinated individuals derived from unvaccinated changes over the epidemic trajectory.

The ratio of the fraction of cases among vaccinated individuals acquired from unvaccinated individuals to the fraction of contacts that occur with unvaccinated individuals is shown over the course of the simulated epidemic. While epidemic spread is ongoing, the fraction of infections among vaccinated individuals that result from contact with unvaccinated individuals is disproportionate to the fraction of contacts with unvaccinated individuals. The expected ratio of 1 , which would occur if vaccinated and unvaccinated individuals contributed proportionately to the number of contacts they make, is shown by the dashed horizontal line for reference. Results are shown for a vaccine efficacy of 0.80 and a mixing coefficient $(\eta)$ of 0.5 , which is equivalent to $10 \%$ of the vaccinated population contacts occurring with unvaccinated individuals.

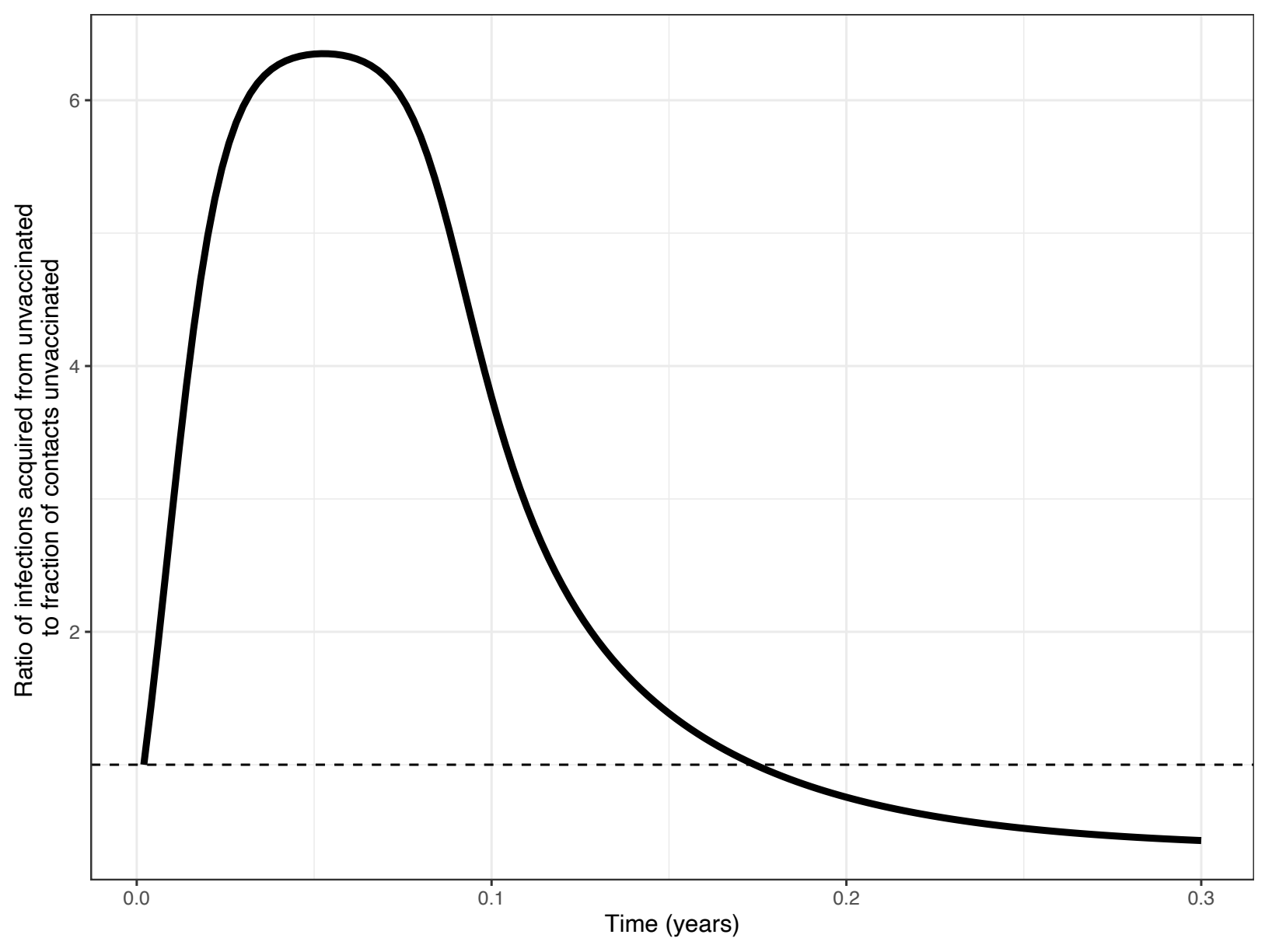


medRxiv preprint doi: https://doi.org/10.1101/2021.12.14.21267742; this version posted December 16, 2021. The copyright holder for this preprint (which was not certified by peer review) is the author/funder, who has granted medRxiv a license to display the preprint in perpetuity. It is made available under a CC-BY-NC-ND 4.0 International license .

Figure 4. Impact of assortativity on contribution to risk and final epidemic size.

Both panels demonstrate the impact of increasing assortativity ( $\eta$, decreased random mixing) on outbreak size among the vaccinated and cumulative contact-adjusted contribution to infection risk in the vaccinated by unvaccinated individuals $(\psi)$. As assortativity increases, the attack rate among vaccinated individuals decreases, but $\psi$ increases. This relationship is seen across a range of (A) initial reproduction numbers and (B) vaccine effectiveness. Base case analysis has $\eta$ of 0.5 , VE of 0.80 and $R$ of 6. 
medRxiv preprint doi: https://doi.org/10.1101/2021.12.14.21267742; this version posted December 16, 2021. The copyright holder for this preprint (which was not certified by peer review) is the author/funder, who has granted medRxiv a license to display the preprint in perpetuity.

It is made available under a CC-BY-NC-ND 4.0 International license .

A
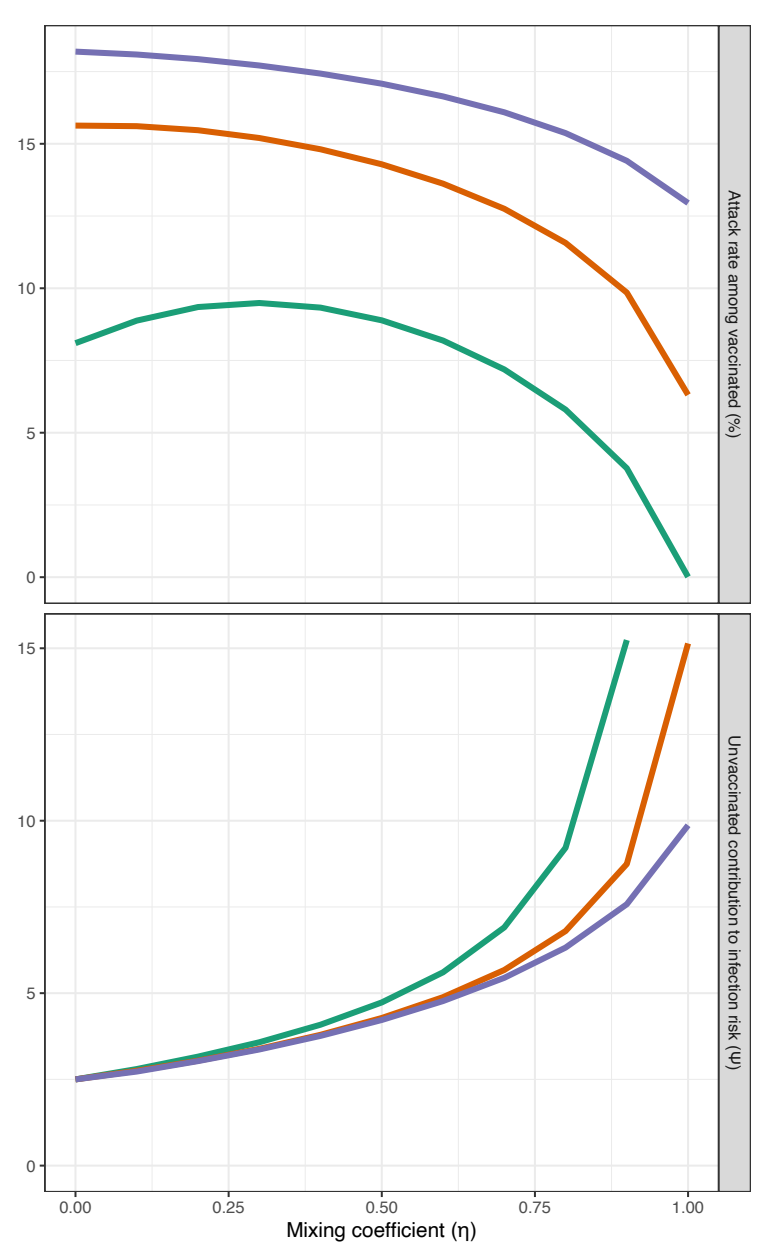

Reproduction number $-4-6-8$
B

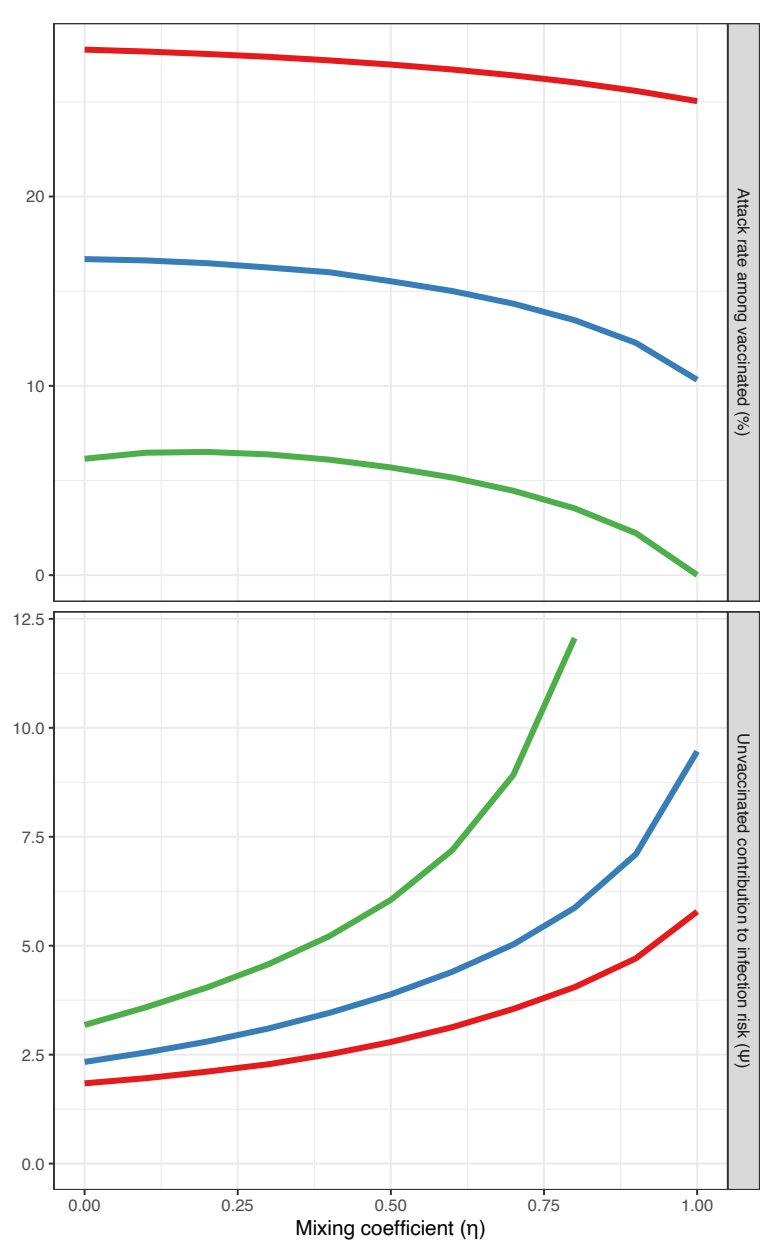

Vaccine effectiveness $-0.7-0.8=0.9$ 


\section{References}

1. Kreier F. 'Unprecedented achievement': who received the first billion COVID vaccinations? Nature. 2021.

2. Mancuso M, Eikenberry SE, Gumel AB. Will vaccine-derived protective immunity curtail COVID-19 variants in the US? Infect Dis Model. 2021;6:1110-34.

3. UK Health Security Agency. SARS-CoV-2 variants of concern and variants under investigation in England. Technical Briefing 31. Available via the Internet at

\section{https://assets.publishing.service.gov.uk/government/uploads/system/uploads/attachment_data/file}

\section{/1040076/Technical_Briefing_31.pdf. Last accessed December 13, 2021. 2021.}

4. Oliu-Barton M, Pradelski BSR, Algan Y, Baker MG, Binagwaho A, Dore GJ, et al. Elimination versus mitigation of SARS-CoV-2 in the presence of effective vaccines. Lancet Glob Health. 2021.

5. Rovetta A. The Impact of COVID-19 on Conspiracy Hypotheses and Risk Perception in Italy: Infodemiological Survey Study Using Google Trends. JMIR Infodemiology. 2021;1(1):e29929.

6. de Sousa AFL, Teixeira JRB, Lua I, de Oliveira Souza F, Ferreira AJF, Schneider G, et al. Determinants of COVID-19 Vaccine Hesitancy in Portuguese-Speaking Countries: A Structural Equations Modeling Approach. Vaccines (Basel). 2021;9(10).

7. Basch CH, Meleo-Erwin Z, Fera J, Jaime C, Basch CE. A global pandemic in the time of viral memes: COVID-19 vaccine misinformation and disinformation on TikTok. Hum Vaccin Immunother. 2021;17(8):2373-7.

8. Hollingsworth P, Van Horne R. 'There's quite a bit of scope to do this in a time of pandemic' legal expert says of vaccine mandates. Available via the Internet at 
medRxiv preprint doi: https://doi.org/10.1101/2021.12.14.21267742; this version posted December 16, 2021. The copyright holder for this preprint (which was not certified by peer review) is the author/funder, who has granted medRxiv a license to display the preprint in perpetuity.

It is made available under a CC-BY-NC-ND 4.0 International license .

https://atlantic.ctvnews.ca/there-s-quite-a-bit-of-scope-to-do-this-in-a-time-of-pandemic-legal-

expert-says-of-vaccine-mandates-1.5617486. Last accessed November 16, 2021. CTV News.

2021 October 8, 2021.

9. Delgado J. Republicans pitch stripping Surgeon General of vaccine mandate power.

Available via the Internet at https://floridapolitics.com/archives/473253-republicans-pitch-

stripping-surgeon-general-of-vaccine-mandate-power/. Last accessed November 16, 2021.

Florida Politics. 2021 November 16, 2021.

10. Garnett GP, Anderson RM. Sexually Transmitted Diseases And Sexual Behavior:

Insights From Mathematical Models. The Journal of Infectious Diseases.

1996;174(Supplement_2):S150-S61.

11. Greenhalgh T, Jimenez JL, Prather KA, Tufekci Z, Fisman D, Schooley R. Ten scientific reasons in support of airborne transmission of SARS-CoV-2. Lancet. 2021;397(10285):1603-5.

12. Earn DJ, Rohani P, Bolker BM, Grenfell BT. A simple model for complex dynamical transitions in epidemics. Science. 2000;287(5453):667-70.

13. Dushoff J, Plotkin JB, Levin SA, Earn DJ. Dynamical resonance can account for seasonality of influenza epidemics. Proc Natl Acad Sci U S A. 2004;101(48):16915-6.

14. Tuite AR, Fisman DN, Greer AL. Mathematical modelling of COVID-19 transmission and mitigation strategies in the population of Ontario, Canada. CMAJ. 2020;192(19):E497-E505.

15. Xia F, Yang X, Cheke RA, Xiao Y. Quantifying competitive advantages of mutant strains in a population involving importation and mass vaccination rollout. Infect Dis Model. 2021;6:988-96.

16. Sleat D, Innes K, Parker I. Are vaccine passports and covid passes a valid alternative to lockdown? BMJ. 2021;375:n2571. 
medRxiv preprint doi: https://doi.org/10.1101/2021.12.14.21267742; this version posted December 16, 2021. The copyright holder for this preprint (which was not certified by peer review) is the author/funder, who has granted medRxiv a license to display the preprint in perpetuity. It is made available under a CC-BY-NC-ND 4.0 International license .

17. Wolfel R, Corman VM, Guggemos W, Seilmaier M, Zange S, Muller MA, et al.

Virological assessment of hospitalized patients with COVID-2019. Nature. 2020;581(7809):465-

9.

18. Little N. COVID-19 Vaccination Tracker. Available via the Internet at https://covid19tracker.ca/vaccinationtracker.html. Last accessed December 10, 2021. 2021. 19. Higdon MM, Wahl B, Jones CB, Rosen JG, Truelove SA, Baidya A, et al. A systematic review of COVID-19 vaccine efficacy and effectiveness against SARS-CoV-2 infection and disease. medRxiv. 2021:2021.09.17.21263549.

20. Statistics Canada. Population estimates, quarterly. Table: 17-10-0009-01 (formerly CANSIM 051-0005). Available via the Internet at https://www150.statcan.gc.ca/t1/tb11/en/tv.action?pid=1710000901. Last accessed May 29, 2020. 2020. 